\title{
p63 regulates growth of esophageal squamous carcinoma cells via the Akt signaling pathway
}

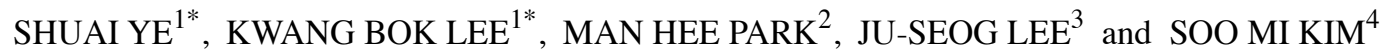 \\ ${ }^{1}$ Department of Orthopedic Surgery, Chonbuk National University Medical School and Hospital, Jeonju; \\ ${ }^{2}$ Catholic University of Pusan, Busan, Republic of Korea; ${ }^{3}$ Department of Systems Biology, University of Texas \\ M.D. Anderson Cancer Center, Houston, TX, USA; ${ }^{4}$ Department of Physiology, Institute for Medical Sciences, \\ Chonbuk National University Medical School, Jeonju, Republic of Korea
}

Received January 22, 2014; Accepted March 27, 2014

DOI: $10.3892 /$ ijo.2014.2374

\begin{abstract}
. p63 is a member of the p53 protein family and plays a crucial role in epithelial development. p63 is expressed in many types of tumors including esophageal cancer; however, its function in cancer is controversial and its role in esophageal cancer has not been clearly established. In the present study, we aimed to identify the mechanisms by which p63 promotes proliferation of esophageal squamous carcinoma cells. Four human esophageal cancer cell lines (TE-8, TE-12, BE3 and OE33) were used in this study. We found that $\Delta \mathrm{Np} 63$ was the predominantly expressed p63 isoform in esophageal squamous cancer cells. Silencing of p63 mRNA in the esophageal cancer cell lines TE- 8 and TE-12 resulted in significant inhibition of cell proliferation in a dose-dependent manner. A colony formation assay also showed that colony formation by TE- 8 and TE-12 cells was significantly inhibited by p63 siRNA. Furthermore, p63 siRNA significantly suppressed p-Akt and induced Akt expression in esophageal squamous carcinoma cell lines. On the other hand, overexpression of p63 in the esophageal cell lines BE3 and OE33 increased p-Akt expression. Silencing of p63 in TE- 8 and TE-12 cell lines induced p53 and p27 expression and suppressed cyclin D1 and cyclin E1 expression, whereas overexpression of p63 in BE3 and OE33 cell lines resulted in decreased levels of p53 and p27 and increased levels of cyclin D1 and cyclin E1. Taken together, our results suggest that p63 may play a pivotal role in the progression of esophageal squamous carcinoma cells through regulation of the cell cycle via the Akt signaling pathway.
\end{abstract}

Correspondence to: Dr Soo Mi Kim, Department of Physiology, Chonbuk National University Medical School, 2-20 Keum-AmDong-San, Jeonju 561-180, Republic of Korea

E-mail: soomikim@jbnu.ac.kr

*Contributed equally

Key words: esophageal cancer, p63, p53, p27, Akt, cell cycle

\section{Introduction}

Esophageal squamous carcinoma (ESC) is the sixth most common cancer among males and the ninth most common cancer among females worldwide $(1,2)$. Many environmental influences and genetic factors have been implicated in ESC development. Because of the high rate of metastasis and invasion of surrounding tissues in the early stages of ESC, the overall 5-year survival rate of this cancer is less than $14 \%(1,3)$. Although ESC arises from the alteration of gene function, the molecular events required for tumorigenesis have not been clearly elucidated.

p63, a member of the p53 family, plays a role in the processes of cell proliferation, survival and differentiation (4). p63 is a transcription factor that is known to be a key regulator of epidermis development and epithelial cell differentiation $(4,5)$. In the esophagus, p63 plays an important role in differentiation and morphogenesis (4). The roles of p63 in the formation of epithelial structures during development have been reported in several studies (6-8); for example, p63 knockout mice exhibit striking developmental defects including abnormal formation of stratified epithelium of the esophagus and skin (6-8). In particular, the esophageal lining of these mice shows a pseudostratified columnar appearance that indicates a critical role for p63 in the regulation of esophagus formation (7). Since the human p63 gene was cloned, two isoforms of p63 that either contain an $\mathrm{N}$-terminal transactivation domain (TAp63) or lack this domain $(\Delta \mathrm{Np} 63)$ have been identified $(4,9) . \Delta \mathrm{Np} 63$ is overexpressed in a variety of human cancers, including head and neck, lung, breast, esophagus and bladder tumors $(10,11)$. The TAp63 and $\Delta$ Np63 isoforms perform different functions. It is clear that the $\Delta \mathrm{Np} 63$ isoform promotes survival of cells and the TAp63 isoform induces cell death; however, the function of p63 in esophageal cancer is still controversial.

The PI3K/Akt pathway is a key regulator of differentiation in a number of cell types including esophageal cells (12). Activation of Akt has been found in a variety of types of cancer including esophageal squamous carcinoma (13-15). However, there is limited information on the relationship between p63 and Akt in cancer progression, and especially on its role in ESC. In this study, we examined whether p63 regulates the Akt pathway during ESC progression. We show 
that the two different p63 isoforms are expressed at variable levels in esophageal cancer cells and provide evidence that p63 promotes ESC cell growth through regulation of the cell cycle and Akt signaling pathway.

\section{Materials and methods}

Cell culture and reagents. Human esophageal cancer cell lines (TE-8, TE-12, BE3 and OE33) were obtained from the University of Texas M.D. Anderson Cancer Center (Houston, TX, USA). p63 siRNA, GAPDH siRNA, and the negative control non-target siRNA vector were obtained from Dharmacon Thermo Scientific (Walthan, MA, USA). Oligofectamin and Opti-MEM were obtained from Invitrogen Life Technologies (Carlsbad, CA, USA). The esophageal cancer cell lines (TE-8, TE-12, BE3 and OE33) were maintained in DMEM/F12 medium (Gibco Life Technologies, Carlsbad, CA, USA) containing $10 \%$ heat-inactivated fetal bovine serum (FBS, Gibco Life Technologies) with $100 \mu \mathrm{g} / \mathrm{ml}$ penicillin and $100 \mu \mathrm{g} / \mathrm{ml}$ streptomycin. The cells were cultured in a humidified atmosphere containing $5 \% \mathrm{CO}_{2}$ at $37^{\circ} \mathrm{C}$. Antibodies against p63, $\Delta$ Np63, TAp63, p53, p27, cyclin D1, cyclin E1, Akt, p-Akt and GAPDH were purchased from Cell Signaling Technology (Danvers, MA, USA).

Knockdown of endogenous p63 in TE-8 and TE-12 cell lines. TE- 8 and TE-12 cells were transfected with 100 or $200 \mathrm{nM}$ of p63 siRNA in $175 \mu \mathrm{l}$ Opti-MEM. Transfection was carried out using $4 \mu \mathrm{l}$ oligofectamin reagent according to the manufacturer's protocol.

p63 overexpression in BE3 and OE33 cell lines. For the preparation of retroviral supernatants, $1 \times 10^{6} 293 \mathrm{~T}$ cells were seeded into 60-mm dishes and transient transfections were performed with Fugene-6 (Roche, CA, USA) following the manufacturer's recommendations. Briefly, $12 \mu$ l of Fugene- 6 was mixed with $188 \mu 1$ of DMEM and incubated at room temperature for $5 \mathrm{~min}$. For retroviral overexpression of p63 in BE3 and OE33 cell lines, Mig-DNA or Mig-p63 vector $(2 \mu \mathrm{g})$, and the packaging vectors pVMUC $(1.8 \mu \mathrm{g})$, and pMD2G $(0.2 \mu \mathrm{g})$, respectively, were mixed with DMEM and Fugene-6. GFP-positive cells with overexpression of p63 were sorted by flow cytometry.

MTT assay for cell proliferation. The cell proliferation assay was performed as previously described (16). Briefly, TE-8 and TE-12 cells were plated at a density of $5 \times 10^{4}$ cells/well in 96-well plates and maintained for $24 \mathrm{~h}$ at $37^{\circ} \mathrm{C}$ with $5 \% \mathrm{CO}_{2}$. At the end of siRNA transfection, $50 \mu 1$ of MTT [3-(4,5-dimethylthiazol2,5-diphenyl)tetrazolium bromide; $2 \mathrm{mg} / \mathrm{ml}$ ] was added to the culture medium of growing cells at the indicated time points and the cells were incubated for a further $3 \mathrm{~h}$. Dimethylsufoxide (200 $\mu \mathrm{l} /$ well) was added and absorbance was measured at $570 \mathrm{~nm}$ using a model Epoch microplate reader (Bio-Tech, CA, USA).

Soft agar colony formation assay. The soft agar colony formation assay has been described previously (17). Briefly, control and p63 siRNA-transfected TE- 8 and TE- 12 cells (5x10 4 cells) in $2 \mathrm{ml} 0.7 \%$ agar with DMEM/F-12 were plated on top of
$1 \%$ bottom agar in 6 -well plates. The covering medium was replaced every 3 days. The cells were incubated at $37^{\circ} \mathrm{C}$ in a humidified $5 \% \mathrm{CO}_{2}$ atmosphere for 2 weeks. Colonies were counted under a microscope and photographed.

Western blot analysis. The expression of cell cycle proteins in esophageal cancer cells was measured by western blotting. Cells were seeded in a 6 -well plate at a density of $2 \times 10^{5}$ cells/well. Cells were washed with PBS and harvested, and the cell pellets were lysed in ice-cold PRO-PREP ${ }^{\mathrm{TM}}$ (Intron Biotechnology, Korea). Proteins were separated by $10 \%$ sodium dodecyl sulfate polyacrylamide gel electrophoresis (SDS-PAGE) and transferred to PVDF membranes (GE Healthcare Life Sciences, Buckinghamshire, UK). Immunoblotting was performed with primary antibodies against p63, $\Delta$ Np63, TAp63, cyclin D1, cyclin E1, p53, p27, Akt and p-Akt. Immunoreactivity was detected using a chemiluminescence kit (Amersham, Arlington Heights, IL, USA).

Statistical analysis. The data were expressed as mean \pm SE for MTT assay and soft agar colony formation assay. Comparisons among the experimental groups were performed using two-way ANOVA with the Student's t-test. P-values $<0.05$ were considered statistically significant.

\section{Results}

Effect of 563 on survival and proliferation of esophageal cancer cells. To investigate the role of p63 in ESC cell proliferation, p63 was silenced by RNA interference. As shown in Fig. 1, the growth rates of TE- 8 and TE-12 cells transfected with p63 siRNA were significantly inhibited in a dose- and timedependent manner compared with cells transfected with empty vector. At $48 \mathrm{~h}$, the growth of TE- 8 and TE-12 cells transfected with $200 \mathrm{nM}$ p63 siRNA was significantly lower than that of cells transfected with empty vector. At $72 \mathrm{~h}$, TE-8 and TE-12 cells transfected with 100 and $200 \mathrm{nM}$ of p63 siRNA showed even more significant inhibition of proliferation compared with the control transfected cells. In addition, silencing of p63 in TE- 8 and TE- 12 cells resulted in a significant decrease in the number of colonies formed in soft agar compared with transfection with empty vector (Fig. 2). Thus, the soft agar colony formation assay confirmed that silencing of p63 inhibited the proliferation of EAC cells.

Effect of p63 silencing on isoforms of p63 in esophageal cancer cells. Several p63 isoforms exist. To determine which isoforms of p63 were affected by p63 silencing, we measured protein expression levels of $\triangle \mathrm{Np} 63$ and TAp63 in TE-8 and TE-12 cells after p63 silencing. Both $\Delta$ Np63 and TAp63 proteins were expressed in non-transfected TE- 8 and TE-12 cells (Fig. 3) although the $\Delta \mathrm{Np} 63$ protein appeared to be dominantly expressed in EAC cells. Silencing of p63 significantly decreased the expression of $\Delta \mathrm{Np} 63$ in TE-8 and TE-12 cells, but had less effect on TAp63 protein levels.

Effect of p63 on cell cycle progression in esophageal cancer cells. Based on the cell viability response to p63 silencing in esophageal cancer cells, we further investigated the role of p63 in the regulation of cell cycle progression by silencing 
TE-8

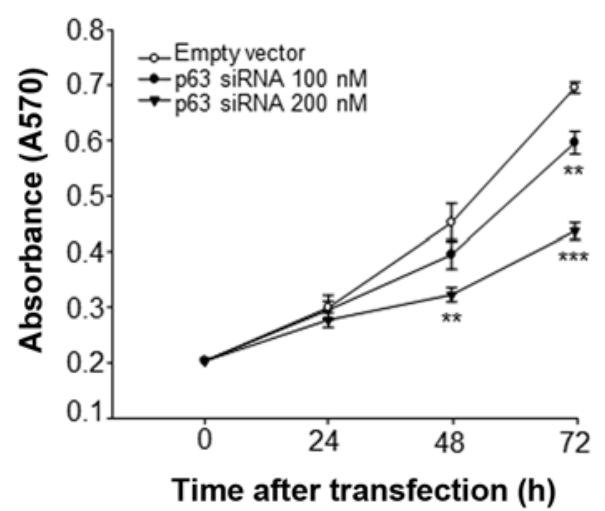

TE-12

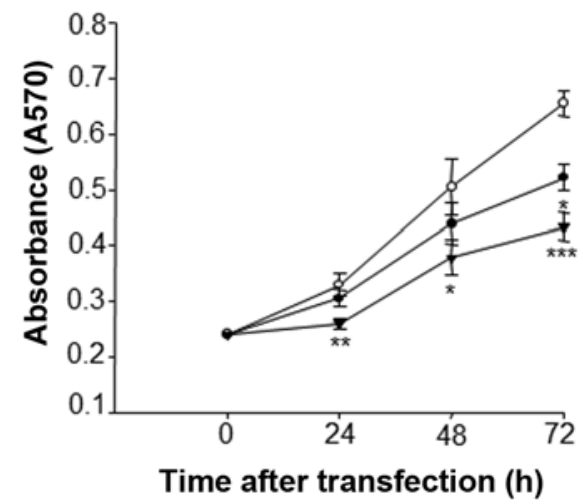

Figure 1. Effects of p63 silencing on esophageal cancer cell proliferation. TE-8 and TE-12 cells were transiently transfected with p63 siRNA (100 and $200 \mathrm{nM}$ ). After transfection with p63 siRNA for $0,24,48$ and $72 \mathrm{~h}$ in TE- 8 and TE- 12 cells, cell proliferation rates were measured by MTT assay. Data are presented as mean \pm SEM and two-way ANOVA followed by Student's t-test was used for comparison among groups. ${ }^{*} \mathrm{P}<0.05,{ }^{* * *} \mathrm{P}<0.01,{ }^{* * * *} \mathrm{P}<0.001$ compared with the empty vector.

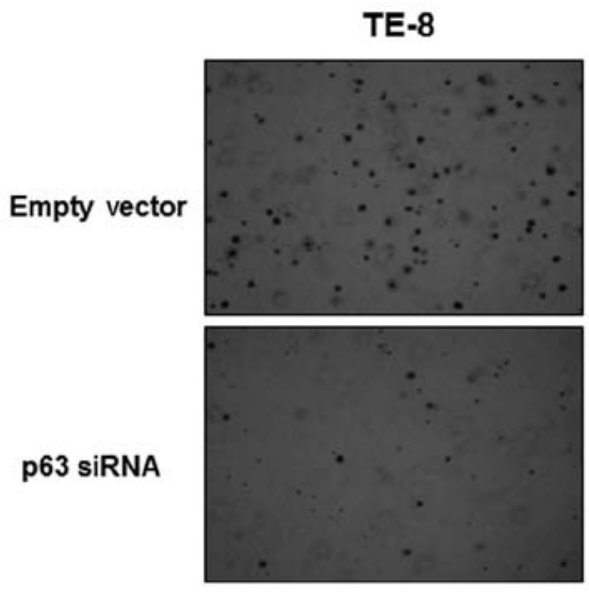

TE-8

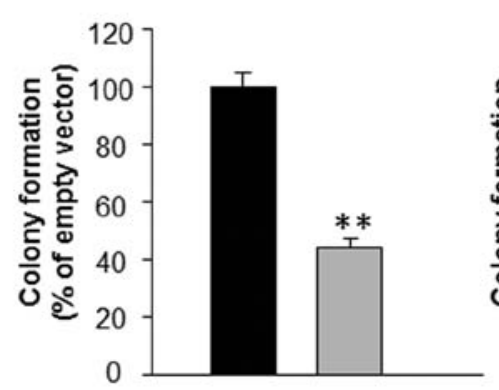

TE-12

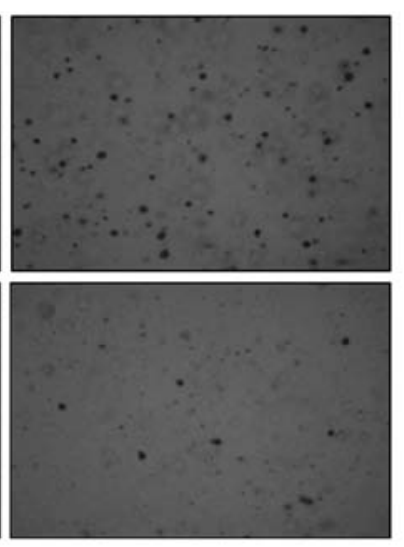

TE-12

Figure 2. Colony formation assay. The number of colonies derived from TE-8 and TE-12 cell cultures transfected with empty vector or p63 siRNA (200 nM) was counted. Each value represents at least three independent experiments. Values shown were normalized to empty vector cells and represent mean \pm SEM. Student's t-test was used for comparisons between empty vector and p63 siRNA $\left({ }^{*} \mathrm{P}<0.05,{ }^{* *} \mathrm{P}<0.01,{ }^{* * * *} \mathrm{P}<0.001\right)$.

p63 in TE- 8 and TE- 12 cells. At $24 \mathrm{~h}$ after p63 silencing, the expression of p53 and p27 proteins was significantly increased in TE-8 and TE-12 cells whereas expression of cyclin D1 and cyclin E1 decreased in both cell lines (Fig. 4). We further investigated the regulation of cell cycle-related proteins in two additional esophageal cancer cell lines that do not normally express p63, BE3 and OE33, which overexpressed p63. As shown in Fig. 5, p53 and p21 protein levels were significantly reduced by overexpression of p63 in BE3 and OE33 cells, whereas expression of cyclin D1 and cyclin E1 was induced, contrary to the results for p63 knockdown cell lines. Taken together, these data confirm our hypothesis that p63 is an 
TE-8

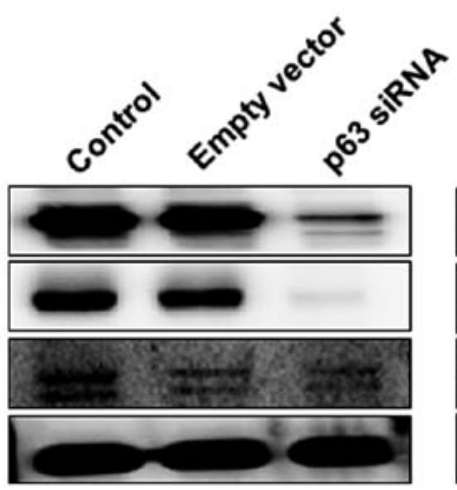

TE-12

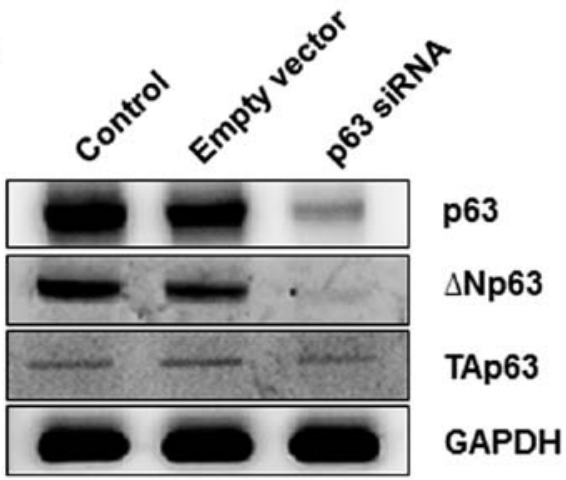

Figure 3. Expression of $\Delta \mathrm{Np} 63$ and TAp63 protein isoforms in esophageal cancer cells after transfection with $200 \mathrm{nM} \mathrm{p} 63$ siRNA for $72 \mathrm{~h}$. All western blotting data are representative of at least three independent experiments. GAPDH was used as an internal control.

TE-8

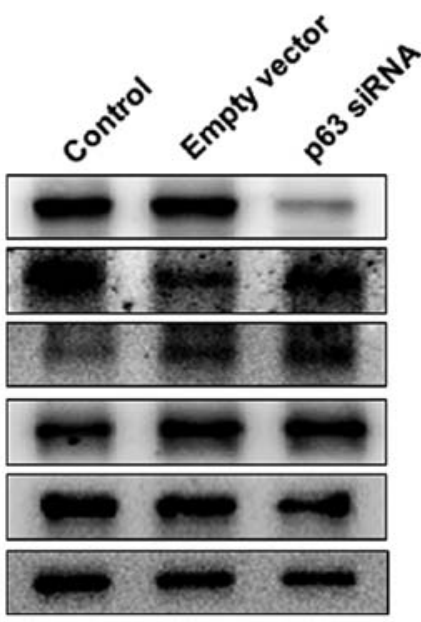

TE-12

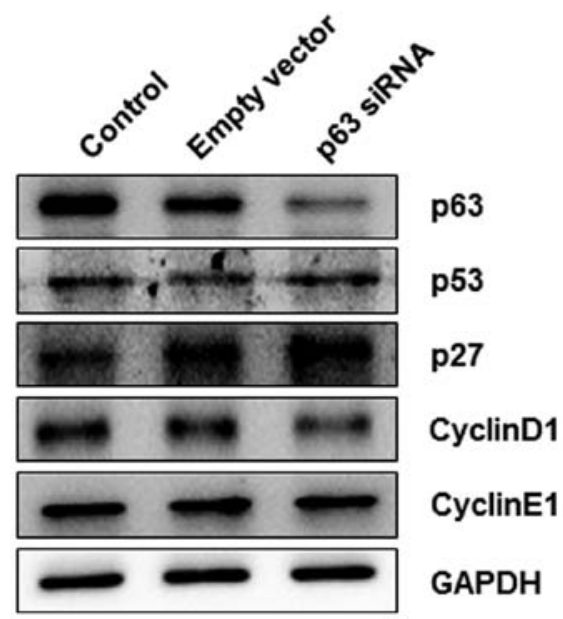

Figure 4. Silencing of 063 alters the expression of regulatory components involved in $\mathrm{G}_{1} / \mathrm{S}$ phase of the cell cycle. TE- 8 and TE-12 cells were transfected with empty vector or p63 siRNA $(200 \mathrm{nM})$. Cells were harvested at $12 \mathrm{~h}$. All western blotting data are representative of at least three independent experiments. GAPDH was used as an internal control.

BE3

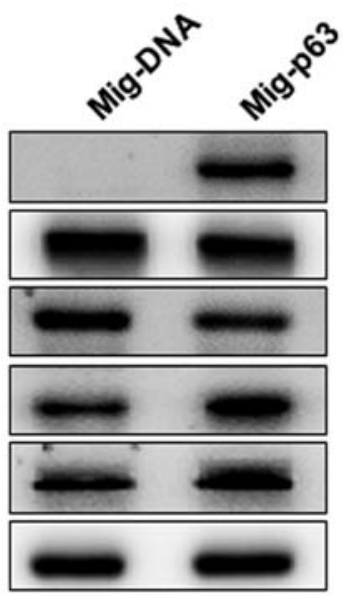

OE33

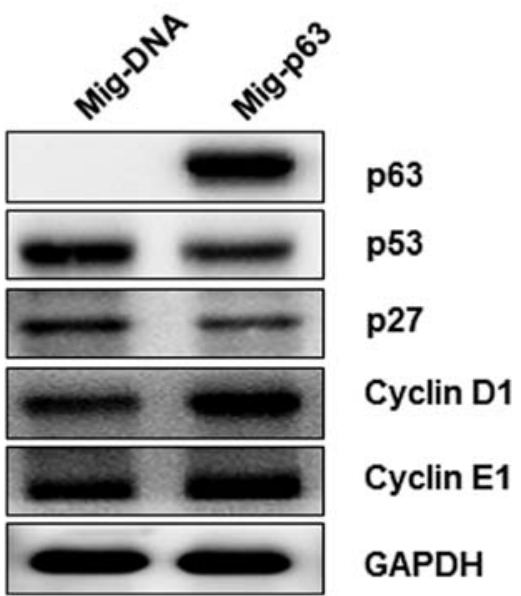

Figure 5. Overexpression of p63 alters the expression of regulatory components involved in the $\mathrm{G}_{1} / \mathrm{S}$ phase of the cell cycle. Mig-DNA and Mig-p63 were overexpressed in BE3 and OE33 cells. All western blotting data are representative of at least three independent experiments. GAPDH was used as an internal control. 
A

TE-8

TE-12
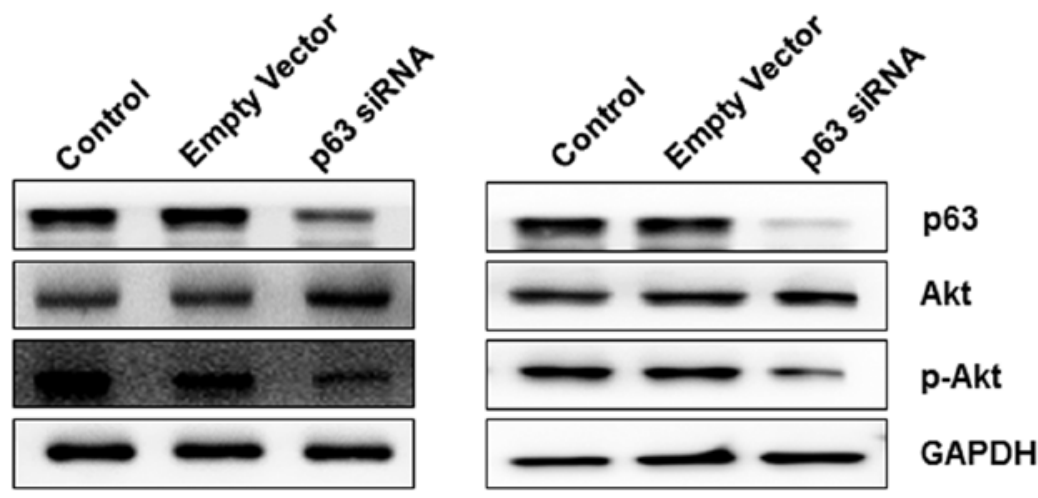

B
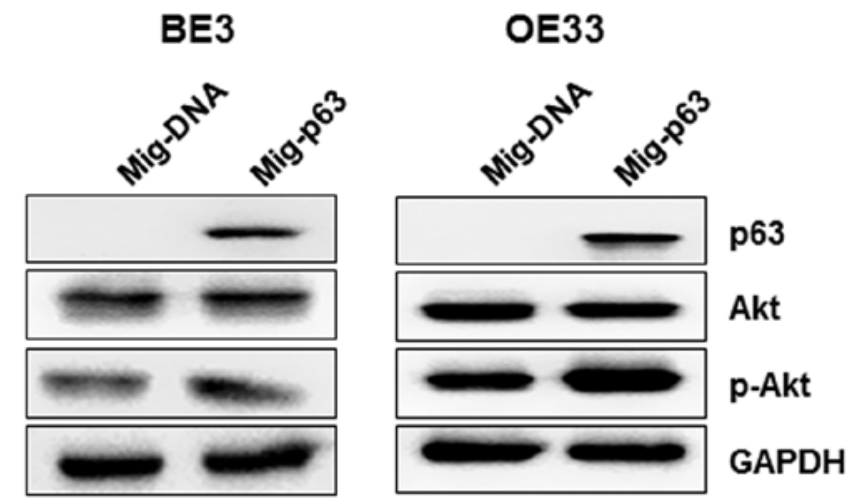

Figure 6. Effect of p63 on Akt pathway proteins. Cells were immunoblotted with antibodies against Akt and p-Akt. Silencing of p63 in TE-8 and TE-12 cells inhibited the expression of p-Akt at $72 \mathrm{~h}$ (A). Overexpression of p63 in BE3 and OE33 cells increased the expression of p-Akt at $72 \mathrm{~h}$ (B). All western blotting data are representative of at least three independent experiments. GAPDH was used as an internal control.

important regulator of proliferation and cell cycle progression in esophageal cancer cells.

Effect of p63 on Akt signaling in esophageal cancer cells. To assess the function of p63 in the regulation of Akt signaling during esophageal tumorigenesis, we examined Akt and p-Akt protein levels after p63 silencing or overexpression in esophageal cancer cells. Silencing of p63 in TE-8 and TE-12 cells resulted in decreased expression of p-Akt and a slight increase in protein levels of Akt in both cell lines (Fig. 6A). Furthermore, as shown in Fig. 6B, overexpression of p63 significantly decreased the expression of p-Akt without affecting Akt levels, contrary to the results for p63 knock down cell lines.

\section{Discussion}

The p63 gene encodes several protein isoforms with homology to the tumor suppressor protein p53 and is an essential regulator of squamous differentiation. p63 is critical for the proliferative potential of epithelial stem cells and is frequently overexpressed in squamous cells including esophageal cancer cells $(7,18-22)$. However, the functional role of p63 in the progression of ESC has not been clearly elucidated. In the present study we found that p63 promotes proliferation of ESC cells through regulation of the $\mathrm{G}_{1}$ phase of the cell cycle and the Akt signaling pathway.
Our study clearly showed that loss of p63 significantly inhibited ESC cell growth in a time- and dose-dependent manner. We also found that loss of p63 significantly decreased colony formation in a soft agar assay, suggesting that p63 functions as an oncogene in ESC cells. Since p63 has multiple isoforms as a result of alternative exon splicing, we examined which p63 isoforms were expressed in the ESC cell lines TE- 8 and TE-12. We found that both $\Delta$ Np63 and TAp63 isoforms were expressed in these EAC cell lines, but $\Delta \mathrm{Np} 63$ was dominantly expressed. Silencing of p63 induced more severe knock down of $\Delta \mathrm{Np} 63$ protein level than that of TAp63, strongly implicating a role for $\Delta \mathrm{Np} 63$ in the progression of ESC. These findings are in agreement with previous reports of the cancer-promoting activity of $\Delta \mathrm{Np} 63$ in many cell types (23-28). In fact, overexpression of $\Delta \mathrm{Np} 63$ has been found in cancers of squamous epithelial origin and has been shown to support tumor survival (23-28). $\Delta \mathrm{Np} 63$ enhances the proliferative capacity of both epithelial stem cells and cancer cells, and loss of p63 reduces the proliferative rate of breast, bladder, pancreas, esophagus, and head and neck cancer cells (23-28). Therefore, $\triangle \mathrm{Np} 63$ is strongly implicated in the survival and maintenance of ESC cells.

Because p63 is a member of the p53 family and interacts with all p53 family members, we further investigated the role of p63 in cell cycle regulation in ESC cells. $\triangle \mathrm{Np} 63$ has been shown to directly bind to the p21 promoter $(29,30)$. 
Moreover, ablation of endogenous p63 expression in human primary keratinocytes increases p21 expression and leads to $\mathrm{G}_{1}$ cell cycle arrest (31). DeYoung et al demonstrated that $\Delta \mathrm{Np} 63$ is required for $\mathrm{G}_{1}$ progression in keratinocytes (32). In the present study, we found that silencing of p63 enhanced the expression of p53 and p27 proteins and decreased the level of cyclin D1 protein in TE-8 and TE-12 cells. The increased expression of cyclin-dependent kinase inhibitors (p53 and p27) by p63 silencing in ESC cells is in agreement with the results of previous studies in keratinocytes. We confirmed these findings by overexpression of p63 in BE3 and OE33 esophageal cancer cells that do not normally express $\mathrm{p} 63$. Overexpression of p63 inhibited the expression of p53 and p27 protein in both cell lines. Cyclin D1 expression was also induced by overexpression of $\mathrm{p} 63$ in BE3 and OE33 cells. These effects contrast with those observed with silencing of p63 and are consistent with earlier studies in mouse keratinocytes, in which reduced p63 levels resulted in decreased cyclin D1 and CDK2 expression $(30,31)$. Together, these findings suggest that p63 regulates the $G_{1}$ phase of the cell cycle in esophageal cancer cells and underscore the importance of p63 in tumor progression in esophageal cancer.

The PI3K pathway is an important regulator of growth in many cell types, including esophageal cells $(12,13)$. PI3K primarily affects cell growth through the Akt pathway, which is frequently altered in esophageal cancer (15). In the present study, we found a strong correlation between regulation of $\mathrm{p} 63$ and Akt activation in esophageal cancer cells: silencing of p63 inhibited activation of Akt and overexpression of p63 resulted in activation of Akt. These findings are consistent with a previous study by Ha et al, in which overexpression of p63 resulted in an increased level of p-Akt in keratinocytes (33). Although our results suggest that regulation of p63 leads to Akt activation in esophageal cancer cells, the mechanism by which p63 activates Akt remains unclear and may be dependent on the activation of PI3K or other molecules upstream of PI3K, or even on currently unknown factors. Further studies are needed to elucidate the mechanisms by which p63 activates the Akt signaling pathway in esophageal cancer cells.

In conclusion, we demonstrated that $\mathrm{p} 63$ promotes the proliferation of ESC cells that is mediated, at least in part, through cell cycle regulation and the Akt pathway. Therefore, our results suggest that p63 plays an important function in the progression of ESC and that molecular targeted therapy against these pathways could be an effective approach against ESC.

\section{Acknowledgements}

This research was supported by the Basic Science Research Program through the National Research Foundation of Korea (NRF) funded by the Ministry of Education, Science and Technology (20110014864 and 2012R1A1A2005729) and by the Korean government (MSIP) (No. 2008-0062279).

\section{References}

1. Guo W and Jiang YG: Current gene expression studies in esophageal carcinoma. Curr Genomics 10: 534-539, 2009.

2. Scott RB, Harrison J, Boulton C, et al: Global attentionalexecutive sequelae following surgical lesions to globus pallidus interna. Brain 125: 562-574, 2002.
3. Enzinger PC and Mayer RJ: Esophageal cancer. N Engl J Med 349: 2241-2252, 2003.

4. Bergholz J and Xiao ZX: Role of p63 in development, tumorigenesis and cancer progression. Cancer Microenviron 5: 311-322, 2012.

5. Wu N, Rollin J, Masse I, Lamartine J and Gidrol X: p63 regulates human keratinocyte proliferation via MYC-regulated gene network and differentiation commitment through cell adhesion-related gene network. J Biol Chem 287: 5627-5638, 2012.

6. Celli J,Duijf P, Hamel BC, et al: Heterozygous germline mutations in the p53 homolog p63 are the cause of EEC syndrome. Cell 99: $143-153,1999$.

7. Mills AA, Zheng B, Wang XJ, Vogel H, Roop DR and Bradley A: p63 is a p53 homologue required for limb and epidermal morphogenesis. Nature 398: 708-713, 1999.

8. Yang A, Schweitzer R, Sun D, et al: p63 is essential for regenerative proliferation in limb, craniofacial and epithelial development. Nature 398: 714-718, 1999.

9. Higashikawa K, Yoneda S, Tobiume K, Taki M, Shigeishi H and Kamata N: Snail-induced down-regulation of DeltaNp63alpha acquires invasive phenotype of human squamous cell carcinoma. Cancer Res 67: 9207-9213, 2007.

10. Deyoung MP and Ellisen LW: p63 and p73 in human cancer: defining the network. Oncogene 26: 5169-5183, 2007.

11. Danilov AV, Neupane D, Nagaraja AS, et al: DeltaNp63alphamediated induction of epidermal growth factor receptor promotes pancreatic cancer cell growth and chemoresistance. PloS One 6: e26815, 2011.

12. Lee HH, Ye S, Li XJ, Lee KB, Park MH and Kim SM: Combination treatment with paclitaxel and doxorubicin inhibits growth of human esophageal squamous cancer cells by inactivation of Akt. Oncol Rep 31: 183-188, 2014.

13. Kim AH, Khursigara G, Sun X, Franke TF and Chao MV: Akt phosphorylates and negatively regulates apoptosis signalregulating kinase 1. Mol Cell Biol 21: 893-901, 2001.

14. Zhang HB, Lu P, Guo QY, Zhang ZH and Meng XY: Baicalein induces apoptosis in esophageal squamous cell carcinoma cells through modulation of the PI3K/Akt pathway. Oncol Lett 5: 722-728, 2013.

15. Lin ML, Lu YC, Chen HY, Lee CC, Chung JG and Chen SS: Suppressing the formation of lipid raft-associated Rac1/PI3K/ Akt signaling complexes by curcumin inhibits SDF-1 $\alpha$-induced invasion of human esophageal carcinoma cells. Mol Carcinog 53: 360-379, 2014.

16. Li XJ, Park ES, Park MH and Kim SM: 3,3'-Diindolylmethane suppresses the growth of gastric cancer cells via activation of the Hippo signaling pathway. Oncol Rep 30: 2419-2426, 2013.

17. Li XJ, Leem SH, Park MH and Kim SM: Regulation of YAP through an Akt-dependent process by 3,3'-diindolylmethane in human colon cancer cells. Int J Oncol 43: 1992-1998, 2013.

18. Yang A, Kaghad M, Wang Y, et al: p63, a p53 homolog at 3q27-29, encodes multiple products with transactivating, death-inducing, and dominant-negative activities. Mol Cell 2: 305-316, 1998.

19. Di Como CJ, Urist MJ, Babayan I, et al: p63 expression profiles in human normal and tumor tissues. Clin Cancer Res 8: 494-501, 2002.

20. Parsa R, Yang A, McKeon F and Green H: Association of p63 with proliferative potential in normal and neoplastic human keratinocytes. J Invest Dermatol 113: 1099-1105, 1999.

21. Leonard MK, Kommagani R, Payal V, Mayo LD, Shamma HN and Kadakia MP: DeltaNp63alpha regulates keratinocyte proliferation by controlling PTEN expression and localization. Cell Death Differ 18: 1924-1933, 2011.

22. Hara T, Kijima H, Yamamoto S, et al: Ubiquitous p63 expression in human esophageal squamous cell carcinoma. Int $\mathbf{J}$ Mol Med 14: 169-173, 2004.

23. Perou CM, Sorlie T, Eisen MB, et al: Molecular portraits of human breast tumours. Nature 406: 747-752, 2000.

24. Matos I, Dufloth R, Alvarenga M, Zeferino LC and Schmitt F: p63, cytokeratin 5, and P-cadherin: three molecular markers to distinguish basal phenotype in breast carcinomas. Virchows Arch 447: 688-694, 2005.

25. $\mathrm{Hu} \mathrm{H}, \mathrm{Xia} \mathrm{SH}, \mathrm{Li} \mathrm{AD}$, et al: Elevated expression of $\mathrm{p} 63$ protein in human esophageal squamous cell carcinomas. Int J Cancer 102: $580-583,2002$.

26. Sniezek JC, Matheny KE, Westfall MD and Pietenpol JA: Dominant negative p63 isoform expression in head and neck squamous cell carcinoma. Laryngoscope 114: 2063-2072, 2004. 
27. Massion PP, Taflan PM, Jamshedur Rahman SM, et al: Significance of p63 amplification and overexpression in lung cancer development and prognosis. Cancer Res 63: 7113-7121, 2003.

28. Weber A, Bellmann U, Bootz F, Wittekind C and Tannapfel A: Expression of p53 and its homologues in primary and recurrent squamous cell carcinomas of the head and neck. Int J Cancer 99: 22-28, 2002.

29. Chatterjee A, Chang X, Sen T, Ravi R, Bedi A and Sidransky D: Regulation of $\mathrm{p} 53$ family member isoform DeltaNp63alpha by the nuclear factor-kappaB targeting kinase IkappaB kinase beta. Cancer Res 70: 1419-1429, 2010.

30. Westfall MD, Mays DJ, Sniezek JC and Pietenpol JA: The Delta Np63 alpha phosphoprotein binds the p21 and 14-3-3 sigma promoters in vivo and has transcriptional repressor activity that is reduced by Hay-Wells syndrome-derived mutations. Mol Cell Biol 23: 2264-2276, 2003.
31. Truong AB, Kretz M, Ridky TW, Kimmel R and Khavari PA: p63 regulates proliferation and differentiation of developmentally mature keratinocytes. Genes Dev 20: 3185-3197, 2006.

32. DeYoung MP, Johannessen CM, Leong CO, Faquin W, Rocco JW and Ellisen LW: Tumor-specific p73 up-regulation mediates p63 dependence in squamous cell carcinoma. Cancer Res 66: 9362-9368, 2006.

33. Ha L, Ponnamperuma RM, Jay S, Ricci MS and Weinberg WC: Dysregulated DeltaNp63alpha inhibits expression of Ink4a/arf, blocks senescence, and promotes malignant conversion of keratinocytes. PloS One 6: e21877, 2011 